\title{
A FACE FEMININA DA POBREZA NO TERRITÓRIO MEIO OESTE CONTESTADO, SANTA CATARINA
}

\section{THE FEMALE FACE OF POVERTY IN THE CONTESTED MIDWEST TERRITORY, SANTA CATARINA}

\author{
Andréia Tecchio \\ Universidade Federal de Santa Catarina, Programa de Pós-Graduação em Agroecossistemas, \\ Florianópolis, SC, Brasil. \\ deiatecchio@yahoo.com.br \\ Kety Carla de March \\ Universidade Estadual do Paraná (Unespar), Campus Paranaguá, \\ Colegiado de História, Paranaguá, PR, Brasil. \\ kety.march@unespar.edu.br.
}

\section{Resumo}

No Brasil, as mulheres conquistaram igualdade jurídica a partir da Constituição de 1988. Nos últimos anos, políticas públicas estatais voltadas para grupos de maior vulnerabilidade social as têm trazido para a centralidade da gestão familiar. É a relação entre essas mulheres e as políticas públicas de enfrentamento à pobreza que este artigo analisa. A pesquisa de campo foi realizada na região Oeste de Santa Catarina, entre abril e maio de 2016. Selecionamos 10 municípios com base nos critérios de diversidade de contextos sociais, econômicos e demográficos e entrevistamos 40 famílias assistidas pelo Programa Bolsa Família e 10 profissionais da assistência social. Utilizamos como método de coleta de dados, entrevistas semiestruturadas. Os resultados da pesquisa indicam que na divisão do trabalho por gênero, as atividades domésticas e cuidados com os filhos ficam a cargo das mulheres e implicam no reforço da situação de pobreza, gerando privações em relação ao trabalho remunerado, uma vez que exigem presença constante nos domicílios. Outra situação de vulnerabilidade é a violência doméstica, que levou algumas mulheres a optarem pelo término do relacionamento afetivo, o que, na maioria dos casos, obrigou-as a arcarem sozinhas com o sustento dos filhos. Outras, temendo represálias, não efetuam denúncias aos órgãos competentes. As mulheres entrevistadas vivem uma maior vulnerabilidade em relação aos homens e embora as políticas públicas implementadas nas últimas décadas tenham melhorados suas condições de vida, não há ações específicas direcionadas à sua emancipação.

Palavras-chave: Pobreza. Políticas Públicas. Emancipação.

\begin{abstract}
In Brazil, women have achieved legal equality since the 1988 Constitution. In the past years, state public policies aimed at groups of greater social vulnerability, have brought women to a central position in family management. It is the relation between these women and the social fragility, articulated to public policies of fighting poverty, that this research
\end{abstract}


analyzes. The field research was performed in the west region of Santa Catarina, between April and May of 2016. We selected ten cities based on criteria of the diversity of social, economic, and demographic contexts and interviewed 40 families assisted by the Bolsa Familia Program, besides ten social assistance professionals. As a data collection method, we used semi-structured interviews. The research results indicate that in the gender division of labor, domestic activities and childcare are the responsibility of women and imply the reinforcement of the poverty situation, generating deprivation about paid work, since they require the constant presence in the homes. Another situation of vulnerability is domestic violence, which led some women to choose to end the affective relationship, which forced them, in most cases, to assume the caring and support of their children. Others, fearing reprisals, do not perform complaints to the competent bodies. The interviewed women live in greater vulnerability than men and although the public policies implemented in the last decades have improved their living conditions, there are no specific actions aimed at their emancipation.

Keywords: Poverty. Public Policies. Emancipation.

\section{Introdução}

No Brasil, sujeitos sociais são constantemente apagados da história por pouco ou nada possuírem, tanto em termos financeiros como em direitos. Esses sujeitos acabam por viver à margem da sociedade, invisibilizados, vitimados pela fome, violência e falta de oportunidades. Pouco se sabe sobre como os pobres vivenciam e representam a pobreza (CONH, 2012), muito menos, quais são as condições de vida das mulheres pobres, grupo ainda mais invisibilizado, tanto pela condição social como pela de gênero, e como são vistas pelas políticas públicas. Com base nessas constatações, o artigo analisa a relação entre as mulheres e as políticas públicas de enfrentamento à pobreza.

Nas últimas décadas, o Estado brasileiro implementou um conjunto de políticas públicas de transferência de renda visando o enfrentamento da pobreza, entre elas, o Programa Bolsa Família (PBF). Outra inovação foi à instituição do Programa Nacional de Desenvolvimento Sustentável dos Territórios Rurais (Pronat) em 2003, pelo então Ministério do Desenvolvimento Agrário (MDA), que entre os seus propósitos, estava o atendimento às populações pobres de municípios rurais. A articulação da temática da pobreza com as políticas públicas territorializadas teve continuidade em 2008, quando o Governo Federal criou o Programa Territórios da Cidadania (PTC). 
A análise tem como recorte geográfico, o Território Meio Oeste Contestado, localizado na região Oeste de Santa Catarina ${ }^{1}$.

Figura 01: Localização geográfica de Santa Catarina no Brasil, com destaque para o Território Meio Oeste Contestado e os municípios compreendidos pela pesquisa
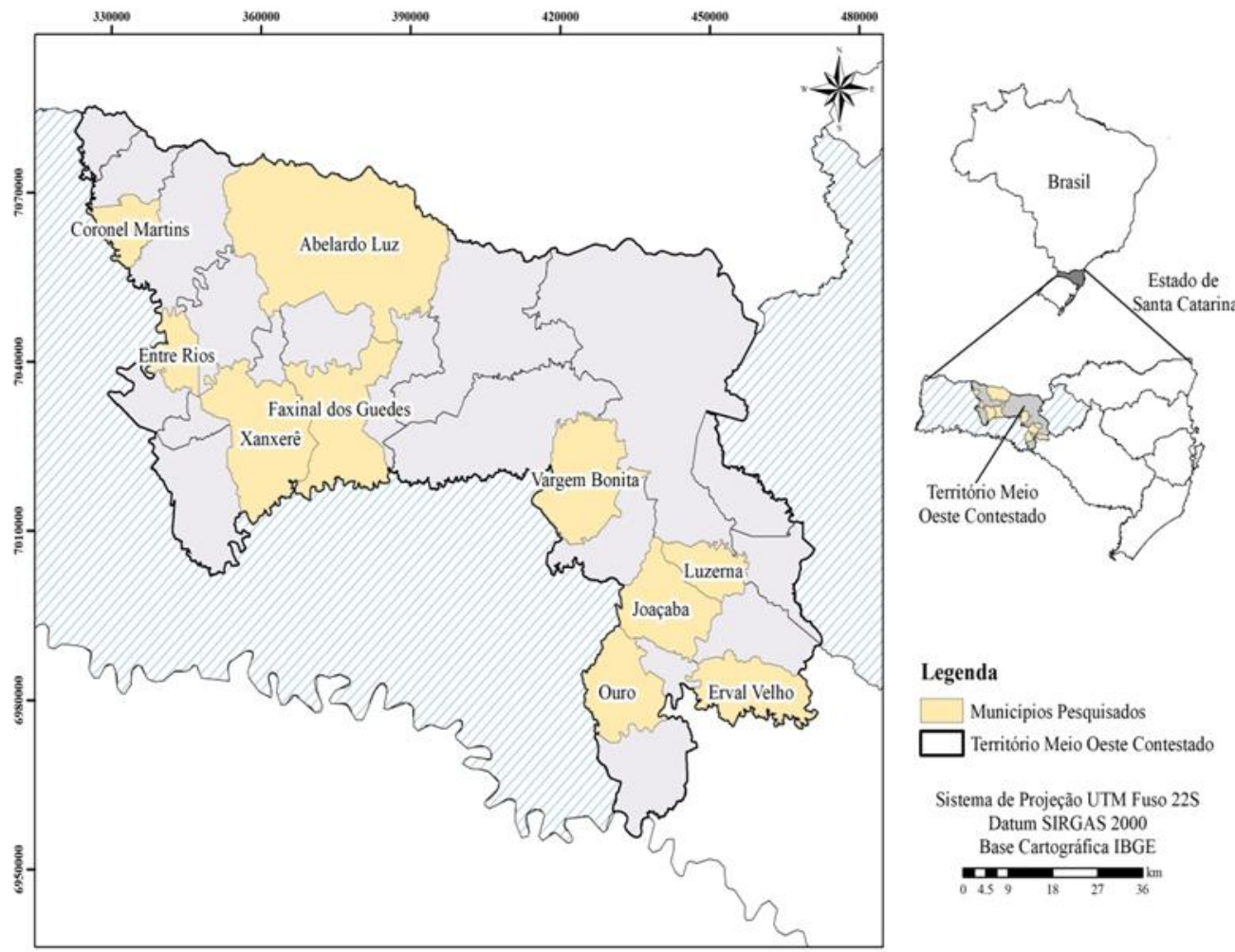

Adaptado de IBGE (2017).

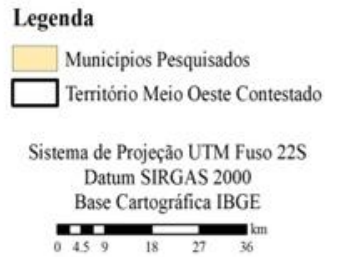

A Figura 01 apresenta a localização geográfica de Santa Catarina no Brasil, do Território no estado, bem como dos municípios que o compõem, com destaque para os 10 municípios onde a pesquisa foi realizada. Este Território foi selecionado por incidir sobre ele o Pronat e o PTC, os quais objetivam, entre outras questões, beneficiar populações pobres. Além disso, o Território agrupa uma parcela significativa de agricultores familiares, de populações tradicionais e de assentados pela reforma agrária que vivem em situação de pobreza, mesmo diante das boas condições socioeconômicas

\footnotetext{
${ }^{1}$ Este artigo baseia-se em temas desenvolvidos pela primeira autora na tese de doutorado, realizada junto ao Programa de Pós-Graduação de Ciências Sociais em Desenvolvimento, Agricultura e Sociedade (CPDA), da Universidade Federal Rural do Rio de Janeiro (CPDA/UFRRJ), intitulada "Pobreza e territorialização da ação pública no Território Meio Oeste Contestado (SC)". Parte do conteúdo deste artigo será publicado no $12^{\circ}$ Seminário Internacional "Fazendo Gênero", que será realizado em 2021.
} 
de Santa Catarina. Em nosso trabalho, utilizamos como método de coleta de dados, entrevistas semiestruturadas e análise de documentos referente aos repasses de recursos financeiros ao Território Meio Oeste Contestado por meio do Pronat e do PTC. O período temporal contemplado compreende a vigência do Pronat (2003 a 2016) e do PTC (2008 a 2016).

A pesquisa de campo foi realizada entre abril e maio de 2016, em 10 municípios do Território, escolhidos com base nos critérios de diversidade de contextos sociais, econômicos e demográficos. No total, entrevistamos 40 famílias assistidas pelo PBF residentes no meio rural e urbano, sendo 38 mulheres e dois homens, além de 10 profissionais da assistência social responsáveis pelo Bolsa Família. A identificação das famílias que melhor atendessem aos nossos critérios de localização (próximas e distanciadas dos centros urbanos) e representação da diversidade das situações de vivência da pobreza, contou com apoio das Secretarias de Assistência Social, uma vez que esta é a instância responsável pelo PBF na esfera municipal ${ }^{2}$.

Praticamente todas as conversas foram realizadas nas casas das famílias e contaram com a participação de mais de um integrante, geralmente filhos, cônjuges e/ou familiares e vizinhos. O tempo que permanecemos conversando com cada família variou de 40 minutos a três horas, pois as pessoas reagiram diferentemente a perguntas sobre o seu cotidiano familiar. Em alguns casos, as respostas foram objetivas, já em outras, a(s) pessoa(s) detalharam situações vivenciadas ou que estavam vivenciando.

$\mathrm{O}$ artigo está dividido em cinco seções, seguidas de considerações finais. $\mathrm{Na}$ primeira seção, apresentamos as principais políticas públicas de enfrentamento à pobreza no Brasil desde o final da década de 1990, procurando compreender a trajetória das mesmas. Isso auxilia no entendimento da interferência das políticas públicas na realidade vivenciada por mulheres pobres no ambiente rural. Na segunda seção, nos dedicamos a compreender o papel dessas mulheres pobres no interior das suas famílias, o que entendem por cuidados familiares, como se relacionam com filhos, como entendem a violência e como estabelecem formas familiares novas, articulando a concepção de "família extensa" e a presença constante de ex-companheiros.

\footnotetext{
${ }^{2}$ Metodologias que se utilizam de entrevistas devem sempre considerar que a escolha dos entrevistados não é definida ao acaso. A representatividade das entrevistadas foi previamente determinada por um órgão institucional e falam também do olhar dessa instituição e as intencionalidades dela diante da pesquisa.
} 
$\mathrm{Na}$ terceira seção observamos as divisões por gênero no universo laboral, a dupla jornada de trabalho e a imposição dos cuidados domésticos e dos filhos às mulheres, o que lhes garante posição inferior aos homens no mercado de trabalho. Também podemos observar nesta seção a percepção de interseccionalidade quando verificamos que as mulheres não exercem as mesmas funções ou estão numa mesma posição no que se refere ao trabalho e à ideia de realização, tendo seus lugares sociais marcados pelo condicionante de classe. Na quarta seção são analisadas as dificuldades enfrentadas pelas mulheres pobres para acessarem benefícios da previdência social. Na quinta e última seção, abordamos a incidência de políticas públicas de enfrentamento da pobreza na vida de mulheres pobres. Por fim, nas considerações finais, sintetizamos os principais resultados da pesquisa e apontamos para as formas de enfrentamento à pobreza vivenciadas pelas mulheres pobres assistidas pelo PBF.

\section{Políticas públicas de enfrentamento à pobreza no Brasil}

O Brasil é um país cujos contornos sociais evidencia uma complexa disparidade em se tratando de distribuição de renda, que produz bolsões de pobreza e desigualdades de acesso a bens e serviços, quando pensamos nos condicionantes de raça e gênero. Diante dessa condição, o Estado brasileiro, entre o fim da década de 1990 e metade da década de 2000, implementou um conjunto de políticas públicas de transferência de renda visando o enfrentamento da pobreza.

No governo de Fernando Henrique Cardoso (1995-2002) foram criados três programas: o Programa Bolsa Escola em 1998, o Programa Bolsa Alimentação em 2001 e o Auxílio Gás em 2002. No início do governo de Luiz Inácio Lula da Silva (2003-2010), foi implementado o Cartão Alimentação. Em outubro de 2003, o governo Lula unificou esses quatro programas em uma única política pública de transferência de renda, o Programa Bolsa Família (COHN, 2012). Em 2016, ano em que a pesquisa foi realizada, se enquadravam na linha da pobreza familiar per capita mensal de até $\mathrm{R} \$ 85,00$ e na linha da pobreza, as que possuíam per capita entre $\mathrm{R} \$ 85,01$ e 170,00.

No PBF, as mulheres são as responsáveis nominais do benefício, bem como para cumprir as condicionalidades impostas (MARIANO, CARLOTO, 2009), que consistem em fazer o Cadastro Único; atualizar este cadastro sempre que houver alguma alteração 
na situação familiar (como mudança de endereço, modificação na composição da família e nos rendimentos); recebimento dos recursos financeiros repassados pelo Governo Federal e aplicação dos mesmos em prol do conjunto familiar; na manutenção das crianças e dos adolescentes de seis a 17 anos na escola; no acompanhamento de saúde de crianças com menos de sete anos, de grávidas e de nutrizes e participação em reuniões e demais atividades programadas pela equipe municipal de assistência social responsável pela execução do PBF (MDS, 2015; MARIANO, CARLOTO, 2009). O PBF se constituiu na principal política pública destinada às populações pobres (CAMPELLO; NERI, 2013; REGO; PINZANNI, 2013).

Em matéria de intervenção pública governamental de enfrentamento da pobreza, outra inovação implementada em 2003, no início do governo Lula, foi a instituição do Programa Territórios Rurais de Identidade, pela recém-criada Secretaria de Desenvolvimento Territorial (SDT), vinculada ao então Ministério do Desenvolvimento Agrário (MDA) ${ }^{3}$. Os territórios rurais de identidade se beneficiaram do Pronat, que tinha entre os seus propósitos, promover o desenvolvimento por meio da internalização de dinâmicas econômicas endógenas nos territórios, que seriam impulsionadas por estratégias de desenvolvimento rural adequadas, as quais incluiriam a formulação e implantação de projetos territoriais estratégicos (LEITE, 2013). De acordo com Bonnal (2013), esse Programa repassava recursos financeiros públicos "não reembolsáveis", para projetos produtivos e de caráter intermunicipal que atendiam organizações de agricultores familiares e a povos tradicionais de um determinado território. Segundo o mesmo autor, o Pronat contemplava a questão da pobreza rural de forma indireta, por meio da ampliação das atividades econômicas e da prática da solidariedade entre o público assistido.

A articulação da temática da pobreza com as políticas públicas territorializadas teve continuidade em 2008, quando o Governo Federal criou o Programa Território da Cidadania, vinculado à Casa Civil da Presidência da República e com participação do MDA na sua gestão e execução. O PTC é um desdobramento do Pronat, tendo como propósito articular em torno de um mesmo território, um amplo conjunto de políticas públicas e de ações oriundas de diferentes ministérios (BONNAL, 2013). O objetivo principal do PTC é a superação da pobreza a partir da promoção do desenvolvimento

\footnotetext{
${ }^{3}$ O MDA foi extinto pelo então Presidente interino Michel Temer em maio de 2016.
} 
econômico com base na geração de trabalho e de renda e na universalização dos programas básicos de cidadania (DELDADO, LEITE, 2011).

Com a extinção do MDA em maio de 2016, não houve destinação de recursos financeiros para o Pronat, tampouco ações voltadas aos territórios da cidadania. Isso significou a interrupção da aplicação de políticas públicas de enfrentamento da pobreza na escala territorial, consequentemente, a ampliação de estruturas coletivas, como creches, o que dificulta ainda mais a vida das mulheres, principalmente das pobres.

\section{O papel das mulheres na família}

A forma com que o PBF vinculou o recebimento e gestão dos recursos financeiros pelas mulheres, melhor discutido adiante, fez com que algumas delas, pela primeira vez, se tornassem sujeitos participativos da vida financeira do núcleo familiar, função historicamente associada aos homens como representantes do universo público e detentores da função de provedores do lar. Muitas dessas mulheres eram trabalhadoras informais, mas não possuíam liberdade de gestão do dinheiro antes de serem assistidas pelo PBF. Mas, quais eram esses núcleos familiares? Como se compunham?

As famílias entrevistadas são compostas, em média, por cinco pessoas. Este índice é superior ao brasileiro que era de 3,34 pessoas/família em 2010 (IBGE, 2010). A grande maioria das mulheres entrevistadas possui conhecimento sobre os métodos anticonceptivos. Como em quase todos os casos, as mulheres titulares do cartão do PBF devem cumprir as condicionalidades desse Programa, e ao frequentarem as unidades de saúde e as reuniões organizadas pelas secretarias de assistência social, recebem informações sobre o planejamento familiar e os métodos anticonceptivos. Não obstante, há diversos motivos por estas famílias terem mais integrantes do que a média nacional.

Para Rego e Pinzani (2013), na visão tradicional, as famílias pobres têm maior quantidade de filhos, na expectativa de um maior número de fontes de renda e, possivelmente, apoio para os pais quando chegarem à terceira idade. Não obstante, os resultados de uma pesquisa conduzida por esses autores no nordeste brasileiro indicam que as famílias pobres são mais numerosas devido a desinformações sobre o controle de natalidade. Além disso, a situação familiar faz com que muitas mulheres não consigam realizar o planejamento sobre o número de filhos, pois "a sujeição das mulheres em uma 
sociedade muito marcada pelo patriarcalismo as priva quase completamente de qualquer soberania sobre seu corpo" (REGO, PINZANI, 2013, p. 179), sendo, dessa maneira, a maternidade imposta pelos maridos ou companheiros.

A sujeição feminina foi percebida pelo filósofo e economista britânico John Stuart Mill, no século XIX. Para Mill (2006, p. 191), “todas as mulheres são educadas, desde os primeiros anos, na crença de que seu ideal de caráter é oposto ao dos homens; nenhuma vontade própria e nenhum domínio sobre si mesmas, mas submissão e sujeição ao controle dos outros". Para Mill as mulheres não só foram treinadas para servir aos homens, mas também para desejar servi-los. Ainda, algumas religiões, como as evangélicas e o catolicismo romano, condenam o uso de métodos anticonceptivos, influenciando as mulheres a não os adotarem (REGO, PINZANI, 2013).

A situação familiar vivida por mulheres cuja gravidez foi desejada pelo marido foi mencionada por quatro das 38 mulheres entrevistadas, principalmente por ocasião do segundo casamento, o que pode ser observado nesse relato: "Eu casei novamente, daí, eu tinha os meus filhos de outro marido, ele [o atual companheiro] tinha um filho de outro relacionamento. Ele quis um filho nosso, daí eu estou grávida" (mulher casada, 38 anos, quatro crianças, doméstica, 3. a série, abril/2016). As mudanças no ordenamento jurídico brasileiro permitem observar novos arranjos familiares que integram casais compostos por uniões anteriormente desfeitas que trazem consigo os filhos do primeiro relacionamento. Novas paternidades e maternidades surgem na medida em que é preciso conformar essa nova condição. Mas esses novos arranjos familiares não excluem os modelos normativos idealizados por esses homens sobre a noção que possuem de masculinidade. March (2015) e Machado (2004) explicam que ter filhos é uma forma de os homens serem reconhecidos em sua masculinidade dentro do grupo social ao qual pertencem, uma vez que a paternidade garantia a eles a passagem do universo da juventude para a vida adulta, demonstrava aos seus pares, potência sexual, capacidade de provimento do lar e posse sobre o corpo da companheira.

Ao mesmo tempo em que aos homens a paternidade é marca simbólica de passagem de uma esfera à outra da vida, também para as mulheres a maternidade era concebida como necessária à concretização da feminilidade. As mulheres entrevistadas estão imersas numa percepção de mundo que vincula felicidade feminina e geração de filhos, pois a maternidade é entendida como sua função essencial: "casamento e 
procriação continuavam a ser o destino da mulher; ser mãe (depois de tornar-se esposa, é claro) conferia-lhe uma posição de prestígio na sociedade, maior que qualquer outra 'carreira"” (SCOTT, 2016, p. 24). Essa percepção tem se alterado nas últimas décadas considerando a quantidade crescente de casais que optaram por não terem filhos. Porém, essa escolha também está marcada por condicionantes como a classe social.

Não obstante, no discurso, as mulheres tenham atribuído aos companheiros o desejo da maternidade, provavelmente elas também a quiseram por concebê-la como correta. Aqui devemos considerar o condicionante de produção da fala dessas mulheres, que contavam sobre suas vidas a pesquisadoras. Possivelmente acreditavam que atribuir ao companheiro à última palavra na relação às aproximava a modelos comportamentais cristalizados para as mulheres e de cujos modelos eram embebidas desde a primeira infância: que deveriam se mostrar conduzidas pelos companheiros no processo de formação familiar e que os concebessem como chefes dessa instituição. Devemos considerar que essa normativa do homem como o chefe familiar era tanto cultural como legalmente instituída no Brasil até a Constituição de 1988, momento em que pela primeira vez homens e mulheres foram igualados juridicamente. Antes disso, na história republicana do Brasil, a primeira legislação civil, o Código Civil de 1916, compreendia os homens como chefes das famílias e tutores de suas esposas e filhos, já que as mulheres possuíam status jurídico semelhante à criança, considerada incapaz.

Essa percepção permaneceu no ordenamento jurídico até 1962 com o advento do Estatuto da Mulher Casada, mas mesmo que naquele momento a legislação tenha aproximado homens e mulheres em direitos e deveres dentro do casamento, só em 1988 foram equiparados. Isso não significa que a mudança legal tenha ocasionado mudança nas experiências pessoais desses sujeitos que, ao que a pesquisa indica, continuam a manter esse modelo assimétrico de posições entre homens e mulheres, ao menos de modo discursivo como narrativa produzida de modo intencional, dadas as circunstâncias da coleta dos dados que não deve ser desconsiderada. Isso significa que, embora falem sobre decisões masculinas na formação familiar, elas não estavam excluídas dessas definições e, dados os modelos aceitáveis de feminilidade, poderiam inclusive desejá-las.

Assumir que só os homens determinavam a composição familiar é dizer que essas mulheres ainda estariam presas ao modelo patriarcal de sociedade que consideraria a sujeição completa do corpo feminino. O modelo patriarcal em que a vontade do patriarca 
era soberana foi se diluindo no século $\mathrm{XX}$, em modelos familiares mais abertos à participação das mulheres no processo decisório, mesmo que por muito tempo ainda prevalecessem assimetrias em virtude, especialmente, da dependência financeira a qual muitas mulheres eram colocadas dentro da relação amorosa, já que a elas era interditado o mundo público e, assim, os afazeres "produtivos" em prol de uma dedicação exclusiva à formação moral dos filhos (SCOTT, 2016).

No entanto, esse modelo "moderno" não atingia de modo prático as classes mais pobres da sociedade em que cada integrante do conjunto familiar precisava contribuir para o sustento financeiro do mesmo. As mulheres apenas eram afastadas dos espaços produtivos quando havia grande oferta de mão de obra masculina ou quando não tinham com quem deixar os filhos pequenos. Além disso, Scott (2016) também aponta para uma redução nas taxas de fecundidade no Brasil que teriam se iniciado em regiões urbanas e industrializadas, mas que vem sendo acompanhada de uma transformação de iguais proporções no ambiente rural e mais empobrecido, local em que por muito tempo famílias numerosas foram sinônimo de oferta de mão de obra.

Ainda, o maior número de pessoas nas famílias pobres entrevistadas em comparação com a média nacional, é explicado pela constatação de que em 10 das 40 famílias inqueridas, uma característica relacionada à composição era a presença de parentes entre os seus integrantes, sendo a maioria crianças, cuja proteção integral, segundo a Lei da Criança e do Adolescente, não estava sendo propiciada pela família natural, formada pelos pais ou qualquer deles, além de seus descendentes (BRASIL, 1990). Nesses casos, a Lei ${ }^{0} 12.010$, de 03 de agosto de 2009 (BRASIL, 2009), dá primazia para que as crianças e adolescentes fiquem com a família extensa, que são os parentes com os quais convivem e mantém vínculos de afinidade e afetividade, como tios e avós, quando houver necessidade de guarda ou adoção.

Outra questão relacionada à composição familiar, é que, das 40 famílias entrevistadas, 13 eram monoparentais. Nesses casos, apenas a mulher, geralmente a mãe, é responsável por prover o sustento familiar, sendo que a maioria delas é "separada", estado civil de quem não vive mais com o(a) companheiro(a). Dessas 13 mulheres, seis mencionaram a violência física e/ou psicológica sofrida como motivo principal do término do relacionamento. A monoparentalidade também está associada a novos modelos familiares. Para Scott (2016), ao contrário do que ocorria até algumas décadas 
atrás, filhos advindos de famílias monoparentais (especialmente devido a separações e divórcios) passaram a não mais serem estereotipados socialmente, uma vez que essas dissoluções e posteriores rearranjos passaram a ser cada vez mais comuns.

No caso em que a mulher sofreu violência física grave, após a agressão, contou com apoio do Estado por meio do atendimento na área da saúde, da assistência social e da Justiça. O Sistema Único de Saúde (SUS) prestou assistência médico-hospitalar durante o período de reestabelecimento do seu quadro de saúde. A assistência social proporcionou atendimento psicossocial e cesta básica, pois como trabalhava informalmente, não contribuía com a Previdência Social, logo não foi beneficiada com o auxílio-doença. A Justiça proibiu o agressor de se aproximar da família após o cumprimento de um período de prisão. Essas medidas, entretanto, não foram suficientes para impedir o agressor de continuar a ameaçar a família, condicionando-a a viver com medo. Esse medo restringe a liberdade sobre o direito de ir e vir, pois, a mulher agredida só sai de casa quando é extremamente necessário.

É importante salientar que nem todas as mulheres entrevistadas que sofreram violência buscaram amparo judicial. De modo geral, justificaram que não há mecanismos eficientes para impedir as agressões que, por sua vez, poderiam se tornar mais severas após denúncia na Justiça. Há, portanto, descrença na capacidade do Estado em garantir a segurança das mulheres agredidas, mesmo diante de leis específicas e mecanismos como as medidas protetivas.

De acordo com Lage e Nader (2016), o Estado brasileiro reconhece a violência contra a mulher como um problema social, praticado, na maioria dos casos, por maridos e companheiros, e tem se esforçado para combatê-la. Entre as medidas adotadas para prevenir e punir os agressores, essas autoras citam a criação de Delegacias Especializadas no Atendimento à Mulher a partir de 1980 e a promulgação da Lei conhecida como Maria da Penha em 2006. Ademais, as diversas organizações feministas atuam no sentido de promover a melhoria das condições de vida das mulheres por meio da luta conta a violência por elas sofrida ou da fiscalização dos serviços públicos que tem essa finalidade. Mesmo assim, o quadro é grave no que concerne à violência física e simbólica praticada contra as mulheres (LAGE, NADER, 2016), o que se agrava quando tratamos do contexto rural, uma vez que muitas vezes essas mulheres não dispõem de mecanismos para 
denúncia, a violência nem sempre possui testemunhas e as relações de propriedade e vinculação à terra dão a elas menor mobilidade para o afastamento ao agressor.

A violência física é a demonstração do direito disciplinar masculino à correção sobre a companheira quando acredita que esta não possui comportamento adequado, seja em relação aos cuidados com os filhos ou com a casa, no trato com terceiros ou na preservação do corpo que não pode ser desejado ou possuído por outros homens (MACHADO, 2004). Só recentemente os estados nacionais, dentre eles o Brasil, passaram a dedicar políticas públicas à proteção das mulheres vítimas de violência por seus parceiros. Por muito tempo, esse tipo de violência nem mesmo era tido como um crime a ser punido, uma vez que socialmente era considerado aceitável na medida em que associava o marido que "corrige" ao pai "educador". Gerações de mulheres foram ensinadas a calarem sobre a violência sofrida, naturalizando-a no interior das relações conjugais como parte do processo formativo da esposa e direito masculino à adequação. Essa forma de violência era "tida como necessária para a manutenção da família e o bom funcionamento da sociedade" (LAGE; NADER, 2016, p. 287).

As mulheres entrevistadas que mencionaram terem sido vítimas de violência, mas optaram por não denunciar às autoridades policiais, compreendem que foram vítimas de um processo violento. Essa postura demonstra alteração nas concepções de "ato correcional" e "violência", evidenciando que essas mulheres não naturalizam a violência sofrida como parte inerente ao casamento, só não tendo procurado a punição do agressor por não acreditarem na eficiência do Estado na sua proteção.

Outra situação comum vivida por mulheres separadas é a imposição da presença dos ex-companheiros na residência. Estes, na ocasião da visita, levam alguns alimentos, contribuem com pequenas quantidades de dinheiro e fazem reformas e consertos na casa. De acordo com assistentes sociais que atuam nos municípios pesquisados, esses homens objetivam não caracterizar a separação ou o divórcio perante a Justiça, evitando, assim, a obrigatoriedade do pagamento da pensão alimentícia aos filhos. De acordo com March (2015), a presença desses homens no espaço doméstico, diz respeito não somente a uma questão econômica, mas também à crença no direito de posse sobre o corpo da ex-mulher, impedindo que outros homens o acessem. O dinheiro que entregam a elas sem que haja uma formalização de pagamento de pensão alimentícia, também confere a esses homens e sensação de propriedade sobre a mulher a quem considera sustentar. 


\section{Ocupações laborais: entre a divisão por gênero e a precariedade}

A análise da estrutura etária dos principais provedores ${ }^{4}$ das famílias inqueridas, indica que praticamente todos estão em idade ativa, ou seja, teoricamente integram o grupo de pessoas que estão aptas para trabalhar, sendo que as mulheres possuem entre 22 e 53 anos, e os homens entre 23 e 59 anos. Para Telles (2013), caracterizar ou tipificar situações ocupacionais junto às pessoas pobres é uma tarefa quase impossível, uma vez que os entrevistados se declaram desocupados ou desempregados por não possuírem carteira de trabalho assinada, mas atuam em atividades informais, às vezes, em mais de uma. Essa mesma situação foi constatada junto às famílias pobres do Território Meio Oeste Contestado, então fizemos a opção de abordar, quando for o caso, apenas as duas atividades mais importantes no que concerne ao tempo dedicado e a renda obtida.

Quase todas as mulheres entrevistadas têm como ocupação principal os serviços domésticos. Entre as mulheres que tem uma ocupação secundária, as que residem no meio urbano fazem faxina, e as que moram no meio rural, trabalham na agricultura por conta própria ou como diaristas. Na divisão do trabalho por gênero, as mulheres ficam responsáveis pelas atividades domésticas, independentemente de desempenharem uma segunda atividade como faxineiras ou trabalhadoras rurais. $\mathrm{O}$ trabalho doméstico consiste em limpar a casa, lavar as roupas, prover os alimentos (plantar, colher ou comprar), preparar as refeições, bem como cuidar de crianças, idosos e familiares doentes.

Segundo Pedro (2016), a reinvindicação da divisão do trabalho doméstico, visto historicamente como uma incumbência feminina, passou a ser questionada pelo movimento feminista no Brasil a partir de 1960. Esse movimento reivindicava o compartilhamento dos serviços domésticos entre mulheres e homens e investimentos do Estado em estruturas coletivas para socializar alguns desses serviços, como por exemplo, a construção de creches que permitiriam o acesso das mulheres ao trabalho formal (PEDRO, 2016). Essas reinvindicações continuam em pauta, pois ainda não foram plenamente atendidas, como observamos ao analisar a vivência laboral das mulheres pobres entrevistadas.

O Programa Território da Cidadania investiu em estruturas coletivas para socializar algumas incumbências femininas, como na construção de creches, pois estudos

\footnotetext{
${ }^{4}$ Consideramos como provedores os indivíduos responsáveis pelo sustento material das famílias.
} 
científicos, a exemplo do realizado por Lavinas, Cobo e Veiga (2010), indicam que a falta dessa política pública é um grande impeditivo da participação de mulheres pobres no mercado de trabalho. Todavia, nem todos os municípios do Território Meio Oeste Contestado foram contemplados, e os que a implementaram geralmente não dispõem de vagas suficientes para atender a demanda existente. Outra dificuldade relacionada ao acesso a esse serviço, segundo as mulheres entrevistadas, diz respeito ao itinerário e aos horários do transporte público, que nem sempre são condizentes com entrada e saída das crianças da creche.

No que concerne à participação das mulheres pobres no mercado de trabalho, Novellino (2004), identificou características como a prevalência de mulheres atuando em trabalho em tempo parcial e/ou temporário, discriminação no pagamento, trabalho em ocupações que exigem menor qualificação e atuação na economia informal. Constatamos na nossa pesquisa diversas situações vivenciadas por mulheres pobres em consonância com os resultados do estudo realizado pela autora.

A responsabilidade pela execução de atividades domésticas se configura como o principal empecilho para cerca de $61 \%$ das mulheres entrevistadas conseguirem trabalho renumerado. Elas não podem se ausentar da residência por longos períodos, além dos meios de transporte serem precários. Segundo as quatro mulheres inqueridas que vivem no meio rural e trabalham na condição de diaristas em atividades agropecuárias, elas são preteridas em relação aos homens nas contratações por serem consideradas detentoras de menor força física. Assim sendo, ficam vulneráveis ao trabalho precário, pois se sujeitam a não receber o pagamento condizente com as tarefas executadas, conforme nos explicou uma trabalhadora rural: "É por dia, ou por empreitada, ou quebrar milho a quatro reais a bolsa. A gente tem que pegar, fazer o quê!” (mulher monoparental, 50 anos, um filho adolescente, doméstica e diarista na agricultura, não alfabetizada, abril/2016). Outras quatro mulheres trabalham na agricultura, especificamente na produção de alimentos para o consumo doméstico, atividade que não garante ingresso de renda, mas é importante na economia doméstica, uma vez que os alimentos produzidos não precisam ser adquiridos no mercado (TECCHIO, et al. 2019).

As mulheres que residem no meio urbano têm mais possibilidade de conseguir trabalho remunerado. Entre as entrevistadas, cinco fazem faxina em alguns períodos da semana em casas localizadas próximas do local onde moram. Isso facilita conciliar o 
trabalho com as atividades domésticas e dispensa o uso do transporte que é deficitário, considerando o fato de que a maioria dos bairros onde as pessoas pobres moram estão distanciados até $10 \mathrm{~km}$ das regiões urbanas centrais, geralmente onde há mais postos de trabalho ofertados. O trabalho como faxineira é precário, por ser informal e instável, tampouco garante renda suficiente para as principais necessidades familiares. Scott (2016) fala sobre a necessidade das mulheres pobres estabelecerem dupla jornada. Mesmo que discorrendo sobre mulheres em ambiente industrial, podemos transpor essa análise para trabalhadoras rurais e/ou domésticas "[...] as mulheres pobres, mesmo alijadas dos postos de trabalho nas indústrias, não deixaram de combinar atividades domésticas com as que pudessem gerar rendimentos para garantir condições mínimas de sobrevivência para sua família" (SCOTT, 2016, p. 20).

Os homens participantes da pesquisa trabalham em atividades agropecuárias, como diaristas, assalariados (criação de suínos, frigorífico e corte de erva-mate), por conta própria ou como diaristas na construção civil. A precarização do trabalho fica por conta da sazonalidade das atividades agropecuárias e da construção civil, pois além de não garantirem renda fixa mensal, na maioria das vezes, são exercidas informalmente.

Recentemente, as famílias que atuam no corte de erva-mate sofreram modificações a partir de ações do Estado. Na região Oeste de Santa Catarina, o corte de erva-mate é um ofício étnico dos caboclos (RENK, 2006) e tradicionalmente praticado por toda a família - homens, mulheres, adolescentes, crianças -, de maneira que estas acampavam perto dos locais de colheita, geralmente de difícil acesso, ficando totalmente privadas de direitos sociais, em especial, da saúde e da educação. Após publicação da Instrução Normativa n. ${ }^{0}$ 91, de 5 de outubro de 2011, que especificou os procedimentos a serem adotados sobre a fiscalização de trabalho em condições análogas a de escravo (DOU, 2011), o Ministério do Trabalho e Emprego aumentou o número de vistorias sobre as condições de trabalho dos cortadores de erva-mate. Segundo as famílias entrevistadas que praticam essa atividade, as ervateiras passaram a empregar os trabalhadores formalmente e a melhorar as condições dos alojamentos, fornecendo-lhes casas equipadas, com no mínimo, energia elétrica, cama e fogão. Além da atuação desse Ministério, a exigência das condicionalidades do PBF mudou a tradição de toda a família ir para o corte de erva-mate. Atualmente, a atividade é exercida apenas pelos homens, que regressam ao domicílio semanal, quinzenal ou mensalmente, a depender da distância 
entre a residência e o local do trabalho, que muda de acordo com os contratos de compra da matéria-prima estabelecidos pela ervateira que os contrata. As mulheres ficam nas casas para que os filhos tenham acesso à saúde e à educação, ou seja, para cumprir as condicionalidades do PBF, condição esta melhor discutida no quinto item.

De maneira geral, as pessoas entrevistadas no Território Meio Oeste Contestado têm uma vida laboral regida pela insegurança e pela instabilidade, pois não conseguem estabilidade laboral, o que dificulta a permanência numa profissão ou ocupação mais definitiva, intercalando atuações em empregos formais e informais. De acordo com Telles (2013), isso leva os trabalhadores pobres a viverem em situação de precariedade e de vulnerabilidade, independentemente se estão na condição de desempregados, de empregados no mercado formal ou informal, ou ainda, se trabalham por conta própria.

Além da precariedade relacionada ao trabalho, diversos relatos foram proferidos durante a pesquisa, sobre o fato de se sentirem incapazes de atuarem em áreas que não exijam força física, como pode ser observado na entrevista a seguir:

\begin{abstract}
Às vezes eu estou trabalhando, fazendo a faxina e limpando o escritório, daí fico olhando as gurias [filhas da patroa] só no computador, fico pensando, sabendo que eu nunca vou ser uma pessoa dessas. A gente vai ser o resto da vida assim, fazendo faxina, limpando o que os outros sujam, a gente nunca vai ser uma pessoa pra viver mexendo no computador. Sempre que estou trabalhando, fico pensando nisso (mulher monoparental, 36 anos, cinco crianças, doméstica e faxineira, não alfabetizada, maio/2016).
\end{abstract}

A análise da própria vida em comparação à vida das filhas da patroa marca o olhar interseccional necessário ao trabalho com perspectivas de gênero no que diz respeito ao trabalho. Não eram todas as mulheres a estarem nas mesmas condições, a ocuparem os mesmos lugares sociais. Da mesma forma que observamos na seção anterior, que a relação entre as mulheres e o modelo de feminilidade dependia da condição social das mesmas, aqui novamente observamos que a condicionante "classe" se impõe uma vez que as realidades vividas pela entrevistada e pelas "filhas da patroa" destoam significativamente. A ascensão social é desejo da primeira que reconhece nas segundas o sucesso simbolizado no domínio da máquina que representa o trabalho intelectual ou burocrático, considerado mais leve e passível de reconhecimento do que o trabalho braçal.

Para Rahnema (2004), as práticas econômicas do mundo moderno desqualificam socialmente os pobres, fazendo-os se sentirem inúteis para a sociedade e perderem a confiança em si, ao mesmo tempo em que as exigências relacionadas ao progresso dificultam o acesso às atividades lucrativas. Na entrevista acima, a mulher se vê no mundo 
como inferior e não considera o seu trabalho importante, porque vê a mudança social representada pelas mulheres no computador.

\section{A incompatibilidade da previdência social com a vida de mulheres pobres}

O acesso universal à Previdência Social, cujo sistema previdenciário tem como princípio a distribuição de renda, foi garantido somente em 1988, no Art. 195 da Constituição Federal, contudo a sua ampliação para os trabalhadores rurais ocorreu somente em 1992 (DELGADO, CARDOSO JR., 1999). Com o intuito de estudar a condição de beneficiários da Previdência Social, a Tabela 01 apresenta informações referentes aos principais provedores do sustento das famílias entrevistadas do Território Meio Oeste Contestado.

\begin{tabular}{|c|c|c|}
\hline Condição de beneficiário & Mulher & Homem \\
\hline Desprovido & 27 & 8 \\
\hline NFPR* & 5 & 3 \\
\hline Indígena & 3 & 2 \\
\hline Carteira assinada & 3 & 11 \\
\hline Contribui com o INSS & 2 & 1 \\
\hline Aposentado & 0 & 2 \\
\hline Total & 40 & 27 \\
\hline
\end{tabular}

Observamos, a partir das informações da Tabela 01, que uma quantidade significativa dos provedores do sustento das famílias ${ }^{5}$ está privada do acesso aos benefícios previdenciários, sendo aproximadamente $68 \%$ das mulheres e $32 \%$ dos homens. De maneira geral, os homens estão mais amparados pela Previdência Social em relação às mulheres, pois, como vimos anteriormente, na divisão do trabalho por gênero, não ficam responsáveis pelas atividades domésticas e pelas condicionalidades do PBF, logo possuem mais liberdade para ingressar no mercado de trabalho formal.

Parte dos trabalhadores (mulheres e homens) que não contribuía oficialmente com a Previdência Social mencionou que, devido a problemas de saúde, não são aprovados

\footnotetext{
${ }^{5}$ Para efeito de aposentadoria, a Previdência Social considera os indígenas como "segurados especiais" a exemplo dos agricultores familiares, ou seja, se aposentam pelo critério de idade (homens: 60 anos e mulheres: 55 anos). De acordo com a Fundação Nacional do Índio (Funai, s/d), a diferença em relação aos demais assegurados especiais é que a comprovação da contribuição se dá por meio da apresentação de uma certidão fornecida pela Funai, certificando a condição de índio como trabalhador rural. Diferentemente das demais pessoas pobres, essa condição confere aos indígenas maior segurança em relação à aposentadoria.
} 
em exames admissionais, tampouco conseguem a aposentadoria por invalidez, ficando condicionados ao trabalho sazonal e informal. Essas pessoas relacionam os problemas de saúde com o fato de terem iniciado a vida laboral ainda quando crianças e aos acidentes de trabalhos sofridos, conforme ilustra a entrevista a seguir:

\begin{abstract}
Eu não posso mais trabalhar, eu tenho problema na minha coluna. Eu não consigo mais trabalhar na roça. Eu cuido da minha hortinha aos poucos e só. [...] Trabalhei demais, desde os meus 10 anos. Então, me estraguei quando eu era nova, a gente erguia peso, o que não podia a gente fazia, roçava mato, olha... de tudo. Até quando a gente se assentou aqui, a gente trabalhou entregando lenha, daí, carregar caminhões e caminhões de lenha. Então, isso prejudicou mais ainda. E hoje não posso mais fazer isso. Desde carpir, não consigo mais, vou roçar, não aguento e não tem como fazer cirurgia na minha coluna, não adianta (mulher casada, 42 anos, dois adolescentes, doméstica, $4 .^{\text {a }}$ série, maio/2016).
\end{abstract}

Segundo famílias entrevistadas, o SUS apresentou melhora significativa na última década, principalmente em relação ao acesso a consultas nas unidades de saúde e ao fornecimento de medicamentos "Esses dias que eu fui lá levar o [nome do filho] consultar que estava com gripe, tinha todos os medicamentos que precisava. [...]. eu também pego anticoncepcional, pego para dois meses. É uma ajuda e tanto!” (mulher casada, 32 anos, três crianças, agricultora, $5^{\text {a }}$. série, maio/2016). As assistentes sociais inqueridas também ressaltaram melhorias no sistema de saúde, provavelmente, devido à ampliação dos investimentos decorrentes das políticas públicas de desenvolvimento territorial. Não obstante, os tratamentos mais complexos, como cirurgias, que possivelmente poderiam resolver, pelo menos em partes, os problemas de saúde, ainda estão aquém da demanda.

Nota-se, a partir das informações da Tabela 01, que a Nota Fiscal de Produtor Rural (NFPR) é a forma de comprovar a contribuição previdenciária para cinco mulheres e três homens. Trata-se de um documento emitido na circulação de produtos ou mercadorias produzidos no estabelecimento agropecuário próprio ou obtido mediante contrato de arrendamento de terras para a produção agropecuária. Como as famílias pobres praticamente não produzem produtos para comercializar, a forma de obter essa nota é estabelecendo contratos "fictícios" de arrendamento de terras com parentes ou vizinhos, bem como para estes utilizarem o bloco fiscal desse arrendatário fictício para fazer transações comerciais. Tecchio, Cazella e Mattei (2011) averiguaram que se trata de uma estratégia de reprodução social adotadas pelas famílias pobres do Território Meio Oeste Contestado, para garantir a condição de segurados da Previdência Social. 
Alguns provedores do sustento das famílias já poderiam estar aposentados por tempo de contribuição ou por idade, mas não conseguiram comprovar a contribuição previdenciária, pois tiveram a carteira assinada durante um período inferior ao exigido para acessar tal benefício, devido à descontinuidade de empregos formais, ou simplesmente, por nunca terem trabalhado formalmente. As mulheres são mais privadas desses benefícios, pois o trabalho doméstico não é considerado uma atividade produtiva, logo chegam à velhice sem estar na condição de seguradas da Previdência Social, além de deixarem de receber o salário-maternidade.

A solução proposta pelo Governo Federal em 2011, para que mulheres e homens de baixa renda que exercem atividades domésticas acessem os benefícios da Previdência Social, foi a criação do "Facultativo de Baixa Renda (dona de casa)". Para tanto, deve ser feita uma contribuição mensal ao Instituto Nacional do Seguro Social (INSS), no valor de 5\% de um salário mínimo, desde que a renda familiar mensal - excetuando os recursos recebidos do Bolsa Família - não ultrapasse dois salários-mínimos (BRASIL, 2017). Como indica a Tabela 01, apenas duas mulheres e um homem aderiram a essa forma de contribuição previdenciária. De maneira geral, as pessoas entrevistadas conheciam os direitos e deveres previdenciários, principalmente por meio das informações prestadas pelas Secretarias de Assistência Social, no entanto mencionaram que não era possível retirar do orçamento doméstico $\mathrm{R} \$ 44,00$ por mês, correspondente aos $5 \%$ do salário mínimo de 2016, cujo valor era de $\mathrm{R} \$ 888,00$.

Para as pessoas pobres, a transferência da renda por meio da Previdência Social garante a manutenção de famílias beneficiárias acima da linha da pobreza, segundo estudos realizados por Delgado e Cardoso Jr. (1999), Camarano e Pasinato (2007) e Lopes, Medeiros e Tecchio (2020), realizados, respectivamente no contexto brasileiro, latino-americano e paraense. Todavia, segundo Cohn (2012), a previdência social foi construída para assistir os setores formais e urbanos do mercado de trabalho. Assim sendo, quando foi ampliada visando ao atendimento das populações pobres e rurais, as regras mostraram-se incompatíveis com a trajetória de trabalho e de vida, vividas ou vivenciadas pelas pessoas. Em suma, em relação à Previdência Social, observamos, no Território Meio Oeste Contestado, o mesmo ciclo vicioso identificado por Cohn (2012, p. 65 e 66): “[...] ausência de oportunidade de trabalho $\rightarrow$ aposentadoria/auxílio doença (no geral, negados) $\rightarrow$ Bolsa Família [...]”. 
Como vimos, a maior dificuldade ao acesso à previdência é vivida pelas mulheres, muitas delas monoparentais. Isso se dá porque em grande parte de suas vidas se dedicam aos trabalhos domésticos, sendo os companheiros (quando os tem) considerados os provedores do lar. Mesmo contribuindo diretamente para a manutenção da família, seus trabalhos em grande maioria eram mal remunerados, em tempo parcial e sem registro formal, uma vez que não possuíam condições de deixarem os cuidados dos filhos a cargo de alguma instituição pública, como uma creche, ou familiares e redes de solidariedade.

\section{A incidência de políticas públicas na vida de mulheres pobres}

Por ser o recorte adotado na pesquisa, todas as famílias entrevistadas são beneficiárias do Bolsa Família. Segundo elas, a transferência de renda por meio desse Programa foi a política que mais contribuiu para a melhoria da qualidade de vida, pois garante a aquisição de parte da "comida grosseira", expressão que se refere aos itens que integram a cesta básica, como farinha, arroz, feijão, óleo e leite, bem como das roupas e dos calçados para as crianças e adolescentes que frequentam a escola.

O PBF elegeu as mulheres como foco das intervenções, por considerar que nas relações de gênero, as mulheres usam o baixo valor monetário que as famílias recebem de maneira mais eficiente e efetiva (LAVINAS; COBO; VEIGA, 2010). Mariano e Carloto (2009) criticam o Estado, pois ao responsabilizar as mulheres pelas condicionalidades do PBF, as tornam menos disponíveis para o mercado de trabalho remunerado e reforça a associação da mulher com a maternidade e as tarefas clássicas da esfera reprodutiva. Para Rego e Pinzani (2013), o recebimento de renda mínima regular proporcionou a primeira oportunidade de gerir recursos financeiros e, a partir disso, aprenderam sobre economia e planejamento. Estas constatações referentes à importância da titularidade do cartão para as mulheres dialogam com os resultados verificados no Meio Oeste Contestado. Ao mesmo tempo em que a responsabilidade pelo cumprimento das condicionalidades, associada a outros fatores, priva as mulheres do mercado de trabalho, significa garantia maior de suprimento das necessidades familiares mais básicas.

As famílias também ressaltaram a importância da melhoria da alimentação escolar por meio do fornecimento de alimentos produzidos pelos agricultores familiares e adquiridos por intermédio da política de inserção pública de alimentos, de maneira específica, do Programa de Aquisição de Alimentos e do Programa Nacional de 
Alimentação Escolar. Uma parte significativa das famílias mencionou que, quando as crianças se alimentam bem na escola, diminui o consumo de alimentos em casa. Isso apesar de representar uma pequena economia na aquisição de comidas, não deixa de ser importante para os domicílios que possuem orçamentos limitados.

Os recursos financeiros aplicados por meio do Programa Territórios da Cidadania no Território Meio Oeste Contestado ampliaram à construção de escolas, creches, unidades de saúde, Centros de Referência da Assistência Social, Centros de Referência Especializado da Assistência Social, entre outros, em bairros periféricos ou em vilas rurais distanciadas dos centros urbanos. Tanto para as famílias como para as assistentes sociais entrevistadas, a proximidade física desses serviços melhorou o acesso à informação, pois nem sempre tinham condições de se deslocar até o centro urbano para esclarecer dúvidas sobre políticas públicas junto à secretaria de ação social. Ademais, quando moram próximas de uma unidade de saúde, podem obter consultas médicas com mais frequência, o que possibilita o tratamento imediato de doenças assim que os sintomas aparecem e fazer consultas de rotina.

Estudos científicos, a exemplo do realizado por Lavinas, Cobo e Veiga (2010), indicam que a falta de creche pública é um grande impeditivo da participação de mulheres pobres no mercado de trabalho. O PTC investiu em estruturas coletivas para socializar algumas incumbências femininas, como na construção de creches. Todavia, nem todos os municípios do Território Meio Oeste Contestado foram contemplados. Não obstante, os que construíram creches, geralmente não dispõem de vagas suficientes para atender a demanda existente, além da questão já mencionada acima, que diz respeito ao itinerário e aos horários do transporte público não ser compatível com a realidade das famílias inqueridas.

No que concerne ao acesso às políticas públicas de inserção produtiva, a grande maioria das famílias rurais entrevistadas nunca acessou crédito rural, não comercializou alimentos por meio das políticas de aquisição pública de alimentos, tampouco recebeu assistência técnica. Além disso, a análise da matriz de ações do Pronat, complementada com as entrevistas às assistentes sociais, indica que nenhum projeto foi destinado às famílias pobres do Território Meio Oeste Contestado. De acordo com Tecchio et al. (2018), as populações pobres do referido Território não possuíam representação nas instâncias de decisão sobre a destinação dos recursos financeiros do Pronat, e os 
representantes do Estado não propuseram nenhuma ação para capitanear parte de recursos financeiros e destiná-los aos segmentos sociais mais pobres, nem contribuíram na sua organização social, para que propusessem algum projeto.

Apenas duas famílias contempladas neste estudo foram beneficiadas pelo Programa Brasil Sem Miséria, implementado em 2011 para apoiar a inserção produtiva de famílias extremamente pobres residentes no meio rural. Alude-se que o referido Programa assistiu poucas famílias por ter uma abrangência reduzida devido às limitações orçamentárias e de a maioria das famílias extremamente pobres não integrar as redes sociotécnicas das organizações rurais responsáveis pela implementação de políticas públicas de desenvolvimento rural. Segundo os estudos realizados por Cazella (2006); Cazella et al. (2016) e Lovatel, Simonetti e Gazolla (2018), de maneira geral, no Brasil, as ações públicas de desenvolvimento rural, mesmo as implementadas como alternativas ao modelo produtivista, beneficiam agricultores familiares melhor estruturados do ponto de vista socioeconômico, e as famílias rurais pobres ficam relegadas às políticas sociais.

As mulheres vivem uma condição de maior vulnerabilidade em relação aos homens e, embora houvesse programas governamentais como o Plano Nacional de Políticas Públicas para as Mulheres visando empoderar e emancipar as mulheres no território brasileiro, para essas mulheres estudadas, essa política pública não foi acessível, provavelmente porque a região não detinha um braço do Estado que pudesse fornecer os caminhos para a concretização dessas ações, o que denota a importância da presença do Estado próximo às populações vulneráveis.

Quase todas as mulheres entrevistadas afirmaram ter suas condições de vida melhoradas a partir do início da década de 2000. Não obstante, as possíveis melhorias não se devem apenas às políticas de enfrentamento da pobreza e de desenvolvimento territorial. Segundo Maluf (2013), desde 2003, o Brasil combinou, embora de maneira modesta, o crescimento do Produto Interno Bruto, com a redução da pobreza e da desigualdade, por intermédio de uma conjugação de instrumentos, entre eles, a recuperação do valor real do salário mínimo e consequentemente dos benefícios da seguridade social, com forte impacto no meio rural; o estímulo a geração de empregos por intermédio de investimentos públicos; a ampliação de programa de transferência de renda e o incentivo à agricultura familiar. 


\section{Considerações finais}

Os resultados da pesquisa indicam que as políticas públicas destinadas ao enfrentamento da pobreza promoveram uma incipiente autonomia às mulheres, principalmente pelo fato de muitas delas ter administrado dinheiro pela primeira vez na vida. Ademais, com o ingresso mensal de renda e melhorias na prestação de serviços públicos, principalmente na área da saúde e educação, a condição de vida das famílias pobres melhorou. Para as famílias, a transferência de renda por meio do PBF foi a política que mais contribuiu para as melhorias da qualidade de vida.

$\mathrm{Na}$ divisão do trabalho por gênero, o fato de serem incumbidas pelas atividades domésticas se configura em implicações que reforçam a situação de pobreza. Uma delas diz respeito às privações que sofrem em relação ao trabalho remunerado, uma vez que as atividades domésticas exigem a presença praticamente constante nos domicílios. As que trabalham fora de casa, por sua vez, o fazem em tempo parcial e são submetidas à dupla jornada de trabalho, pois não se eximem de executar as atividades domésticas. Isso acarreta na falta de autonomia financeira, pois os recursos recebidos pelo Programa Bolsa Família não são suficientes para isso, dificultando, entre outras questões, a contribuição com a Previdência Social.

Outra situação de vulnerabilidade vivenciada pelas mulheres é a violência doméstica, que levou algumas delas a optarem pelo término do relacionamento afetivo, o que, na maioria dos casos, obrigou-as a arcarem sozinhas com os cuidados e o sustento dos filhos. Ainda há aquelas que não confiam na proteção do Estado, e temendo as represálias, nunca efetuaram denúncias aos órgãos competentes.

Observamos que num primeiro momento, as mulheres passam a ser alvo de políticas públicas, especialmente do $\mathrm{PBF}$, a partir da sua condição de mantenedoras da saúde de crianças e não necessariamente pela sua própria condição de pobreza, preservação da saúde de seu corpo e de suas necessidades básicas, o que demonstra a forma como o governo a entendia a partir da maternidade. As famílias entrevistadas praticamente não foram beneficiadas nem pelas políticas de inserção produtivas direcionadas para as famílias pobres, como Pronat e PBSM. Para as mulheres, essas políticas poderiam proporcionar mais renda, pois poderiam ter a aumentada à produção de alimentos para o autoconsumo e/ou para a comercialização. Dito isso em outras 
palavras, as mulheres continuam à margem das políticas públicas no que concerne a promoção da sua autonomia.

\section{REFERÊNCIAS}

BRASIL. Facultativo de Baixa Renda (dona de casa). 2017. 2009. LEI N 12.010, DE 3 DE AGOSTO DE 2009. Presidência da República.

LEI No 8.069, DE 13 DE JULHO DE 1990. Presidência da República. 1990.

BONNAL, Philippe. Referências e considerações para o estudo e a atuação dos programas de desenvolvimento territorial (PRONAT e PTC) na perspectiva da redução da pobreza em territórios rurais. In: LEITE, Sérgio Pereira. (Org.). Políticas de Desenvolvimento Territorial e Enfrentamento da Pobreza Rural no Brasil. Brasília: IICA, 2013, v.19, p. 33-56.

CAMARANO, Ana Amélia; PASINATO, Maria Tereza. Envelhecimento, pobreza e proteção social na América Latina. Papeles de polación, Toluca, v. 13, n. 52, 2007, p. $1-37$.

CAMPELLO, Tereza; NERI, Marcelo Cortês. (Org.). Programa Bolsa Família: uma década de inclusão e cidadania. Brasília: IPEA, 2013. 494 p.

CAZELLA, Ademir Antonio. Contribuições metodológicas da sócio-antropologia para o desenvolvimento territorial sustentável. Eisforia, v. 4, n. especial, p. 225-247, 2006.

CAZELLA, Ademir Antonio, CAPELLESSO, Adinor José, MEDEIROS, Monique, TECCHIO, Andréia, SENCÉBÉ, Yannick, BÚRIGO, Fábio Luiz. Políticas Públicas de Desenvolvimento Rural no Brasil: o dilema entre inclusão produtiva e assistência social. Revista Política \& Sociedade, v. 15, Edição Especial, p. 49-79, 2016.

COHN, Amélia. Cartas ao Presidente Lula: Bolsa Família e Direitos Sociais. Rio de Janeiro: Pensamento Brasileiro, 2012. 189 p.

DELGADO, Guilherme.; CARDOSO, JR. ; José Celso. O idoso e a previdência rural no Brasil: a experiência recente da universalização. IPEA: Rio de Janeiro, 1999. Texto para discussão $n^{\circ} 688$.

DELGADO, Nelson Giordano; LEITE, Sérgio Pereira. Políticas de desenvolvimento territorial no meio rural brasileiro: novas institucionalidades e protagonismo dos atores. Revista de Ciências Sociais. Rio de Janeiro, RJ, v. 54, n. 2, 2011.

DIÁRIO OFICIAL DA UNIÃO - DOU. INSTRUÇÃO NORMATIVA No - 91, DE 5 DE OUTUBRO DE 2011. 2011. 
FUNDAÇÃO NACIONAL DO ÍNDIO - FUNAI. Previdência Social, s/d. Disponível em: <http://www.funai.gov.br/index.php/previdencia-social>. Acesso em: 20 abr. 2017.

INSTITUTO BRASILEIRO DE GEOGRAFIA E ESTATÍSTICA - IBGE. Censo Demográfico 2010. Rio de Janeiro, 2010.

Geociências, Rio de Janeiro: IBGE, 2017.

LAGE, Lana ; NADER, Maria Beatriz. Da legitimação à condenação social. In : PINSKY, Carla Bassanezi ; PEDRO, Joana Maria (Org). Nova história das mulheres no Brasil. São Paulo: Contexto, 1. ed., 2. Reimpressão, 2016, p. 286-312.

LAVINAS, Lena; COBO, Barbará; VEIGA, Alinne. Bolsa Família: impacto das transferências de renda sobre a autonomia das mulheres pobres e as relações de gênero. Revista Latinoamericana de Población, v. 6, n. 10, p. 32, 2012.

\section{LEITE, Sérgio Pereira. (Org.). Políticas de Desenvolvimento Territorial e} Enfrentamento da Pobreza Rural no Brasil. Brasília: IICA, 2013, v.19, 360 p.

LOPES, Marcelo Rodrigues; MEDEIROS, Monique; TECCHIO, Andréia. A aposentadoria rural e a construção da autonomia feminina no território Quilombola de Porto Alegre, Pará. Raízes, Campina Grande, PB, v. 40, n. 2, p. 347-365, 2020.

LOVATEL, Marlise; SIMONETTI, André Luiz; GAZOLLA, Marcio. Vulnerabilidades socioeconômicas e produtivas dos agricultores familiares pobres de Santa Catarina. Revista Brasileira de Desenvolvimento Regional, Blumenau, v. 6, n. 3, p. 147-174, 2018.

MACHADO, Lia Zanotta. Masculinidades e violências: gênero e mal-estar na sociedade contemporânea. In: SCHPUN, M. R. (Org.). Masculinidades. São Paulo: Boitempo Editora. 2004. p. 35-78.

MALUF, Renato. Elementos para uma agenda pública de enfrentamento da pobreza e inclusão sócioprodutiva no meio rural na ótica do desenvolvimento territorial sustentável. In: LEITE, S. P. (Org.). Políticas de Desenvolvimento Territorial e Enfrentamento da Pobreza Rural no Brasil. Brasília: IICA, 2013, v.19, p. 57-88.

MARCH, Kety Carla. “Jogos de luzes e sombras" Processos criminais e subjetividades masculinas no Paraná dos anos de 1950. 2015. 305 p. Tese (Doutorado em História) Universidade Federal do Paraná, Curitiba, PR, 2015.

MARIANO, Silvana Aparecida, CARLOTO, Cássia Maria. Gênero e combate à pobreza: Programa Bolsa Família. Estudos Feministas, Florianópolis, v. 17, n. 3, p. 901-907, 2009.

MILL, John Suart. A sujeição das mulheres. Gênero. Niterói, RJ, v. 6, n. 2, v.7, n.1, p.181-202, 2006. 


\section{MINISTÉRIO DO DESENVOLVIMENTO SOCIAL - MDS. Acesso a educação e} saúde. 2015. Disponível em: <http://mds.gov.br/assuntos/bolsa-familia/o-que-e/acessoa-educacao-e-saude/acesso-a-educacao-e-saude>. Acesso em: 19 fev. 2019.

NOVELLINO, Maria Salet Ferreira. Os estudos sobre feminização da pobreza e políticas públicas para mulheres. In: XIV Encontro Nacional de Estudos Populacionais ABEP, Anais eletrônicos, Caxamú, 2004.

PEDRO, Joana Maria. O feminismo de "segunda onda": corpo, prazer e trabalho. In: PINSKY; Carla Basanezi; PEDRO, Joana Maria (Org.). Nova história das mulheres no Brasil. São Paulo: Contexto, 1. ed., 2. Reimpressão, 2016, p. 238-259.

RAHNEMA, Majid. Quand la misère chasse la pauvreté. Paris: Babel, 2004. 458 p.

REGO, Walquiria Leão.; PINZANI, Alessandro. Vozes do Bolsa Família: autonomia, dinheiro e cidadania. São Paulo: Editora Unesp, 2013. 241 p.

RENK, Arlene. A luta da erva: um ofício étnico da nação brasileira no oeste catarinense. Chapecó: Argos, 2 ed., 2006. 250 p.

SCOTT, Ana Silvia. O caleidoscópio dos arranjos familiares. In: PINSKY, Carla Bassanezi ; PEDRO, Joana Maria (Org.). Nova história das mulheres no Brasil. São Paulo: Contexto, $1^{\text {a }}$. ed., 2. Reimpressão, 2016, p. 15-42.

TECCHIO, Andréia; CAZELLA, Ademir Antonio; MATTEI, Lauro. Estratégias de reprodução social de famílias rurais pobres do Território Meio Oeste Contestado (SC). Raízes, Campina Grande, PB, v. 32, n. 2, p. 68-81, 2011.

TECCHIO, Andréia; CAZELLA, Ademir Antonio; SABOURIN Eric Pierre; CORTES, Geneviève. Estratégias alimentares de famílias pobres no Oeste de Santa Catarina.

Redes: Revista de Desenvolvimento Regional, v. 24, n. 3, p. 217-240. 2019.

TECCHIO, Andréia; CORTES, Geneviève; CAZELLA, Ademir Antonio; BÚRIGO, Fábio Luiz; MEDEIROS, Monique. Territorialização da ação pública de enfrentamento da pobreza: mudanças institucionais e gestão social no Meio Oeste Contestado (SC). In: Gestão e dinâmicas em desenvolvimento territorial. PEREFÁN, Mireya Valencia; GRISA, Catia; TARTARUGA, Iván Peyré; RAMÍRESZ-MIRANDA, César Adrián (Org.). 2018, p. 391-406.

TELLES, Vera da Silva. Pobreza e Cidadania. São Paulo: Editora 34, 2. ed. 167 p. 